\title{
EVALUATION OF THE RELATIONSHIP BETWEEN DENTAL CARIES AND OXIDATIVE STRESS AND ANTIOXIDANT CAPACITY
}

\author{
Ahmet Güzelçiçek ${ }^{1}$, Mahmut Demir ${ }^{1}$, Adnan Kirmit ${ }^{1}$, and MEHMET DOGAN ${ }^{1}$ \\ ${ }^{1}$ Harran University
}

March 31, 2021

\begin{abstract}
Background Dental caries can be affected or altered by the body's oxidant / antioxidant balance and oxidative stress. Aim/Hypothesis To examine the relationship between dental caries and Total Oxidant Status (TOS), Total Antioxidant Status (TAS), and Oxidative Stress Index (OSI). Design The study group consisted of 52 children with dental caries (DMFS/dfs [?] 5), and the control group consisted of 42 healthy children (DMFS/dfs $=0$ ). The saliva samples, unstimulated and mid-morning, were collected from all children. Participants' saliva samples were acquired by spitting for 5 minutes, after which the samples were frozen and stored at $4{ }^{\circ} \mathrm{C}$ and kept at $-80^{\circ} \mathrm{C}$ until analysis. NCSS (Number Cruncher Statistical System) 2007 (Kaysville, Utah, USA) was used for the statistical analysis. Results TOS of the patient group cases were statistically significantly higher than those of the control group $(\mathrm{p}=0,004 ; \mathrm{p}<0,01)$. OSI values of the patient group cases were statistically significantly higher than those of the control group $(\mathrm{p}=0,008 ; \mathrm{p}<0,01)$. Conclusion OSI and TOS as markers of oxidative stress levels were found to be significantly higher in the group of patients with dental caries than in the healthy group.
\end{abstract}

\section{Hosted file}

manuscript.pdf available at https://authorea.com/users/405059/articles/516098-evaluation-ofthe-relationship-between-dental-caries-and-oxidative-stress-and-antioxidant-capacity 


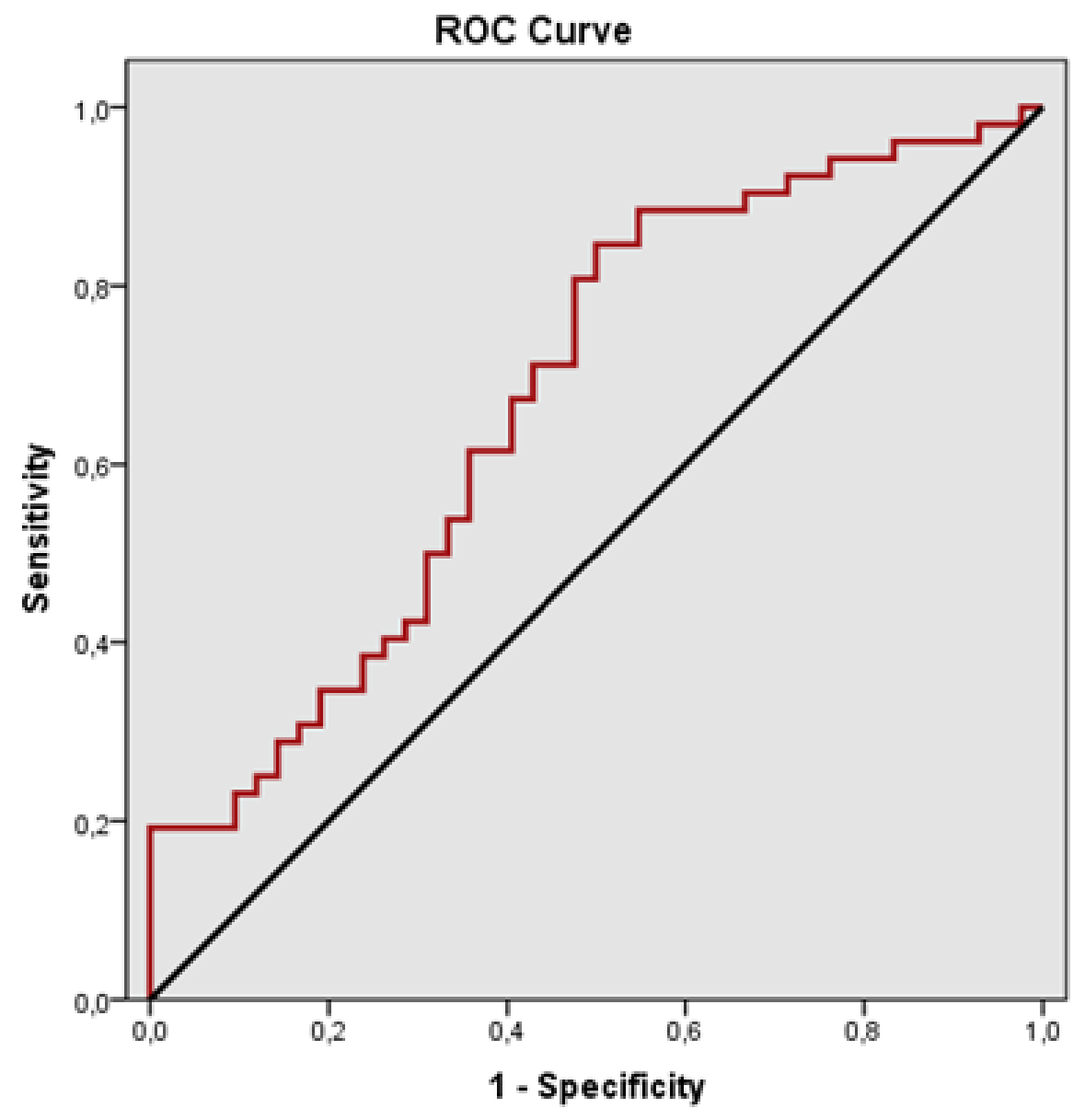




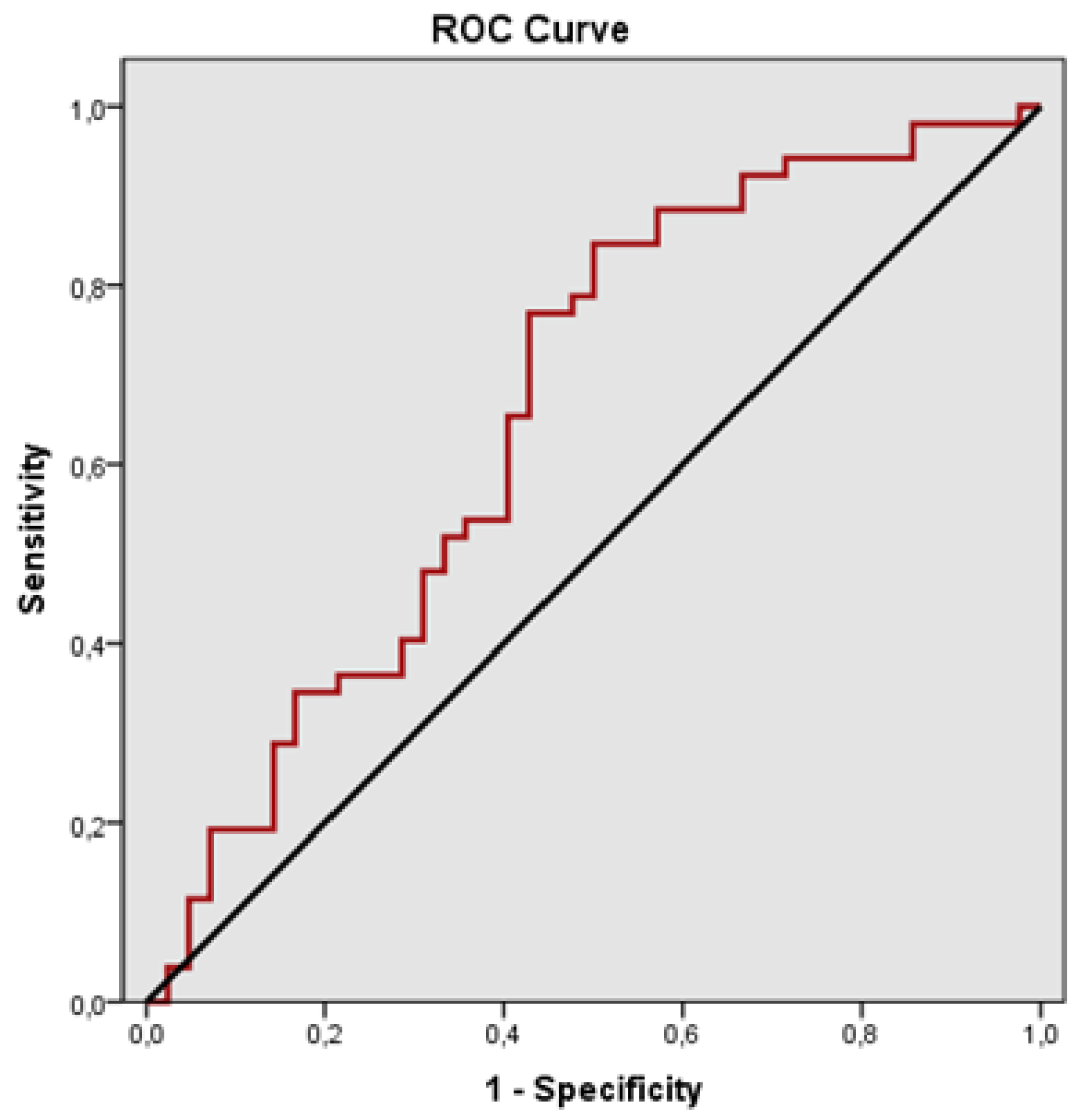

\section{Hosted file}

Table 1.pdf available at https://authorea.com/users/405059/articles/516098-evaluation-ofthe-relationship-between-dental-caries-and-oxidative-stress-and-antioxidant-capacity

\section{Hosted file}

Table 2.pdf available at https://authorea.com/users/405059/articles/516098-evaluation-ofthe-relationship-between-dental-caries-and-oxidative-stress-and-antioxidant-capacity

\section{Hosted file}

Table 3.pdf available at https://authorea.com/users/405059/articles/516098-evaluation-ofthe-relationship-between-dental-caries-and-oxidative-stress-and-antioxidant-capacity

\section{Hosted file}

Table 4.pdf available at https://authorea.com/users/405059/articles/516098-evaluation-ofthe-relationship-between-dental-caries-and-oxidative-stress-and-antioxidant-capacity

\section{Hosted file}

Table 5.pdf available at https://authorea.com/users/405059/articles/516098-evaluation-ofthe-relationship-between-dental-caries-and-oxidative-stress-and-antioxidant-capacity 